\title{
Modelling of emotional exhaustion role on workplace ostracism: A cross-sectional study on Sepah Bank branches in northern provinces of Iran
}

\author{
${\text { Firroz } \text { Yazarloo }^{1}}^{\mathbb{D}}$, Samere Shojaei $^{2^{*}}{ }^{\mathbb{D}}$, Fereydoon Azma $^{(\mathbb{D}}$, Mahmood Reza Mostaghimi $^{\circledR}$ \\ ${ }^{1} \mathrm{PhD}$ Student of Management, Department of Management, Aliabad Katoul Branch, Islamic Azad University, Aliabad Katoul, \\ Iran \\ ${ }^{2}$ Assistant Professor, Department of Management, Aliabad Katoul Branch, Islamic Azad University, Aliabad Katoul, Iran
}

*Corresponding Author: Samere Shojaei, Assistant Professor, Department of Management, Aliabad Katoul Branch, Islamic Azad University, Aliabad Katoul, Iran.Tel: +989112290419, Email: shojaei@aliabadiau.ac.ir

\begin{abstract}
Background and aims: Workplace ostracism is the degree to which a person feels ignored by others in the workplace. This study aimed to evaluate the role of emotional exhaustion on workplace ostracism in Sepah Bank branches in Northern provinces of Iran.

Methods: The present cross-sectional study was conducted as a field survey. The statistical population included 1472 employees of Sepah Bank branches in Northern provinces of Iran. According to the Cochran's sample size formula, 306 individuals were identified as the research sample. The research tool was a 49-item researcher-made questionnaire, the validity of which was confirmed after reviewing the experts' opinions. The reliability of the questionnaire was 0.82 for emotional exhaustion and 0.85 for workplace ostracism. In this study, the structural equation method was used. Data analysis was performed using SPSS and LISREL.

Results: The results of the study showed that the mean of emotional exhaustion and workplace ostracism was 2.31 and 2.57 , indicating an undesirable status of these variables. In addition, emotional exhaustion had a significant effect on the workplace ostracism $(P=0.001$; effect $=0.22 ; \mathrm{t}=3.25)$.

Conclusion: Given the serious impact of emotional exhaustion on workplace ostracism, Sepah Bank should plan programs to reduce emotional exhaustion.

Keywords: Emotional exhaustion, Ostracism, Organization, Work environment
\end{abstract}

Received: 5 February 2020, Accepted: 19 July 2020, ePublished: 30 March 2021

\section{Introduction}

Dynamic organizations, in addition to recognizing and mastering their environments, can anticipate the conditions ahead and make the appropriate planning (1). Interpersonal and inter-organizational interactions, as one of the most important characteristics in today's organizations, play an important role in establishing communication in organizations. One of the important aspects of the dynamics of organizations is to improve the environmental status and to create productive interactions between groups and individuals in the organizations. Organizational rejection is the result of disregard for dynamics in organizations (2). Workplace ostracism is the degree to which a person feels ignored by others in the workplace (3). Exclusion has a detrimental effect on individuals' social and mental performance and a sense of belonging, which is a basic need and can lead to a lack of belonging to the organization and reduce cooperation in the workplace (4). Therefore, neglecting the experience of ostracism, especially in the workplace, is a kind of superficiality.

Research has shown that ostracism can lead to some kind of painful experience, and even its social damage has been likened to physical pain (5-7). Reducing ostracism can decrease employee absenteeism and delays, and improve employees' creativity and innovation (8). This has led to the perception of the need to reduce ostracism in today's organizations as an important issue (9). Ostracism is a psychological phenomenon that not only has primary effects at the individual level and involves the psychologically disadvantaged individual but also has consequences at the group and organizational levels $(10,11)$. A sense of ostracism leads to higher levels of anxiety, burnout, and intention to quit, as well as lower levels of satisfaction, performance, and mental health (1214). Perceptions of ostracism are associated with lower levels of at least three reasons. First, being rejected by others is a painful and negative event, which can lead to severe physical and emotional reactions. Second, people who are rejected experience less social support than others,

C 2021 The Author(s); Published by Shahrekord University of Medical Sciences. This is an open-access article distributed under the terms of the Creative Commons Attribution License (http://creativecommons.org/licenses/by/4.0), which permits unrestricted use, distribution, and reproduction in any medium, provided the original work is properly cited. 
and as social support is an important source of coping with stressful situations, such situations can threaten their health. Third, ostracism eliminates not only social support but also more tangible forms of support, such as stressful situations that can be exacerbated by colleagues' disregard (14-19).

On the other hand, differences in different workplaces have led to failure in creating a uniform version of the workplace ostracism for all organizations. This issue has led to the perception of workplace ostracism as a concern in all organizational environments (20-23). The ambiguity about reducing workplace ostracism in different organizations has led to the lack of targeted planning to reduce workplace ostracism in many organizations today, including banks. Due to their different characteristics, the banks need to specifically study the conditions of workplace ostracism in order to create effective and sustainable planning in this area (24).

In most economies, banks play an important role because they are central to the financial system and are responsible for payments. Hence, the size, structure, and efficiency of the banking sector, which is independent of financial development, are at the center of attention. Therefore, ignoring the issue of ostracism in studies can be the result of the incorrect assumption that ignoring the individual in the organization, especially compared to the thousands of negative behaviors that one encounters in the workplace, is not important.

As the study of theoretical foundations shows, there have been numerous studies on negative workplace behaviors in the organization and various researchers have examined the different aspects of positive and negative organizational behavior, especially in Iran. Accordingly, this study aimed to analyze the dimensions of workplace ostracism and the role of emotional exhaustion. Meanwhile, through providing a model of emotional exhaustion in the workplace, the study attempted to identify the dimensions of emotional exhaustion in Sepah Bank branches in Northern provinces of Iran. In fact, in this study, we examine whether ostracism can be related to emotional exhaustion or not.

\section{Materials and Methods}

The present study is a field survey and applied research, which was conducted in 2019. The study included 130 Sepah Bank branches in three Northern provinces of Iran including Golestan, Mazandaran and Gilan. The statistical population of the study consisted of 1472 employees of Sepah Bank branches in the mentioned provinces. All participants had a minimum of bachelor's degree or higher and their employment status was permanent. Finally, using convenience sampling method and based on Cochrane's sample size formula, 306 individuals were included in the study.

In this way, the statistical population was first identified according to the specified conditions. Accordingly, the statistical population in Golestan province was 428, in Mazandaran 620, and in Guilan 424. Therefore, the research samples were selected according to the statistical population in each province, so that 89 individuals were selected from Golestan, 129 from Mazandaran, and 88 from Guilan. After specifying the number of research samples, the research questionnaires were distributed with the presence of a researcher at the annual conventions organized by Sepah Bank in each province. These conferences were held at different levels of the organization at Sepah Bank for different purposes throughout the year, and the researcher chose the samples by attending conferences and gatherings where participants were eligible for the present study.

Finally, after distributing the questionnaires, 282 questionnaires were analyzed. The research tool was a researcher-made questionnaire designed according to the theoretical foundations in this field that were supervised by experts. The questionnaire had 49 questions, 29 of which measured emotional exhaustion and 20 questions measured workplace ostracism. The emotional exhaustion components in the questionnaire included disinterest in the workplace (6 questions), loss of emotional strength (6 questions), apathy toward clients (7 questions), depersonalization (5 questions), and decreased or lack of personal activity (5 questions). The questionnaire also measured components of workplace ostracism, including supervisor rejection (8 questions), peer rejection (9 questions), and conversational rejection (3 questions).

The questions were designed based on a 5-point Likert scale, in which the score of 5 was considered as very high, 4 as high, 3 as average, 2 as low, and 1 as very low.

The scope of the research questionnaire score in the field of emotional exhaustion was between 29 and 145, and the score of the research questionnaire in the field of workplace ostracism was between 20 and 100 .

Content validity was investigated in various ways, including experts' opinions without statistical analysis, and experts' opinion with statistical analysis. The content validity of these questionnaires was evaluated using the opinions of seven university professors. Moreover, the content validity of this questionnaire was confirmed by content validity forms and content validity index. According to the number of professors, the relative content validity was higher than 0.99 and the content validity index was higher than 0.79 . Therefore, the content validity of the questionnaire was confirmed. The construct validity of the questionnaire was assessed by confirmatory factor analysis. All factor loadings in confirmatory factor analysis were higher than 0.5 and the t-value of all relationships was more than 1.96. Cronbach's alpha was used to evaluate the reliability of the questionnaire, which was 0.82 for emotional exhaustion and 0.85 for workplace ostracism. Descriptive statistics were used for frequency 
and percentage. The structural equation method was also used in the inferential statistics section. Data analysis was performed using SPSS software version 20 and LISREL version 9.2. The $P$ value equal to 0.05 was considered as significant.

\section{Results}

According to descriptive data, 236 (83.7\%) participants were male and 46 (16.3\%) were female. Moreover, 87 (30.9\%) participants had a bachelor's degree or lower, $150(53.2 \%)$ had a master's degree, and $45(16.0 \%)$ had a $\mathrm{PhD}$. Regarding age, 41 (14.5\%) participants were under 30 years old, $140(49.7 \%)$ were 31-40 years old, and 101 (35.8\%) were over 41 years old.

The skewness and the kurtosis calculation were used to determine the distribution status of the research data. The results showed that among all the variables of the study, the kurtosis ranged between 3 and -3 and the skewness was between 5 and -5 . Therefore, the data were normally distributed and the use of covariance-based structural equation methods was allowed due to the existence of its preconditions. The results showed that the mean of emotional exhaustion was 2.31 and the mean workplace ostracism was 2.57. Table 1 shows the status of the components of emotional exhaustion and workplace ostracism.

The results of the present study showed that 'lack of interest in the workplace', 'apathy toward clients', 'decrease or lack of individual success', 'rejection by supervisors', and 'rejection by conversation' were significantly higher than the average level. The structural equation method was used to investigate the relationships among research variables. Figure 1 shows the research model in standard coefficients mode and Figure 2 shows the research model in the case of $\mathrm{T}$ coefficients.

According to our results, emotional exhaustion had a significant effect on workplace ostracism among Sepah Bank employees in Northern provinces of Iran. The effect was 0.22 , and considering the amount of $t$ test, which is 3.25 , it was found that this effect was significant. Structural equation fitting indices in covariance-based software were used to evaluate the suitability of the present research model. Table 2 shows the results of the fitting indices of the above model.

\section{Discussion}

The results of present study showed that the lack of interest in the workplace' at Sepah Bank in the Northern provinces of Iran was at a good level and the 'loss of emotional strength' was at an average level. Moreover, the variables of 'apathy toward clients', 'depersonalization', and 'decrease or lack of individual success' were in poor conditions.

Few studies have addressed this issue and examined the status of emotional exhaustion. Amiri et al (28) determined that job burnout among bank employees is in poor condition, which is in line with our results. Thompson et al found that planning and investing in emotional exhaustion can improve the status of these components. They also found that many organizations did not pay attention to this issue in their priorities, which lead to problems with emotional exhaustion (29). It seems that the lack of attention to emotional exhaustion and lack of prioritization in Sepah Bank have caused this variable to be in an undesirable condition. In interpreting this issue, it is worth noting that Sepah Bank's lack of planning for emotional exhaustion and its management in its organization has led to various components of this variable, including apathy towards clients in the workplace, depersonalization and decrease or lack of individual

Table 2. Report on fitting indices of the research model about role of emotional exhaustion on workplace ostracism

\begin{tabular}{lccc}
\hline Fitting indices & Extent & Standard rate & Status \\
\hline RMSEA & 0.063 & Lower than 0.070 & Confirmed \\
$\chi^{2} / d f$ & 2.13 & Lower than 3 & Confirmed \\
CFI & 0.93 & Higher than 0.9 & Confirmed \\
IFI & 0.95 & Higher than 0.9 & Confirmed \\
NNFI & 0.96 & Higher than 0.9 & Confirmed \\
GFI & 0.91 & Higher than 0.9 & Confirmed \\
AGFI & 0.93 & Higher than 0.9 & Confirmed \\
\hline
\end{tabular}

The results of the research fitting indices showed that all the indices of the research model were in good condition, which indicates the suitability of the research model.

Table 1. One sample $t$ test results of emotional exhaustion and workplace ostracism

\begin{tabular}{|c|c|c|c|c|c|c|c|}
\hline Components & Number of questions & Mean & Expected mean & SD & $t$ test & df & $P$ value \\
\hline Lack of interest in the workplace & 6 & 3.46 & 3 & 1.383 & 5.680 & 281 & $0.001^{*}$ \\
\hline Loss of emotional strength & 6 & 2.86 & 3 & 1.214 & -1.815 & 281 & 0.071 \\
\hline Apathy toward clients & 7 & 2.27 & 3 & 0.674 & -18.089 & 281 & $0.001^{*}$ \\
\hline Depersonalization & 5 & 2.56 & 3 & 1.297 & -5.598 & 281 & $0.001^{*}$ \\
\hline Decrease or lack of individual success & 5 & 2.04 & 3 & 0.863 & -18.492 & 281 & $0.001^{*}$ \\
\hline Rejection by supervisors & 8 & 1.92 & 3 & 0.797 & -22.559 & 281 & $0.001^{*}$ \\
\hline Rejection by colleagues & 9 & 3.77 & 3 & 1.159 & 11.201 & 281 & 0.071 \\
\hline Rejection by conversation & 3 & 1.14 & 3 & 0.505 & -61.518 & 281 & $0.001^{*}$ \\
\hline
\end{tabular}




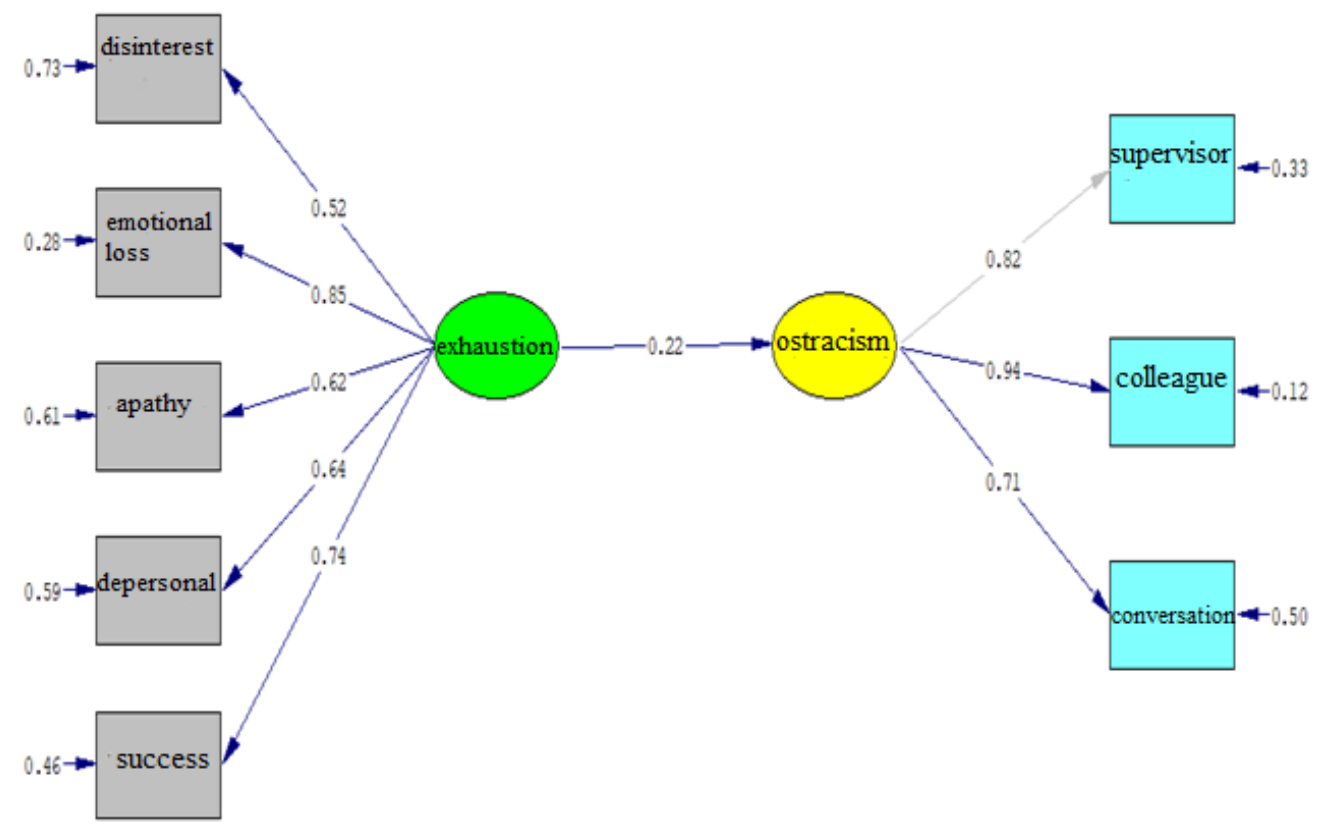

Chisquare $=40.48$, , $d=19$, P-value $=0.00283$, RMISEA $=0.063$

Figure 1. Research Model on Standard Coefficients Mode about Role of Emotional Exhaustion on Workplace Ostracism.

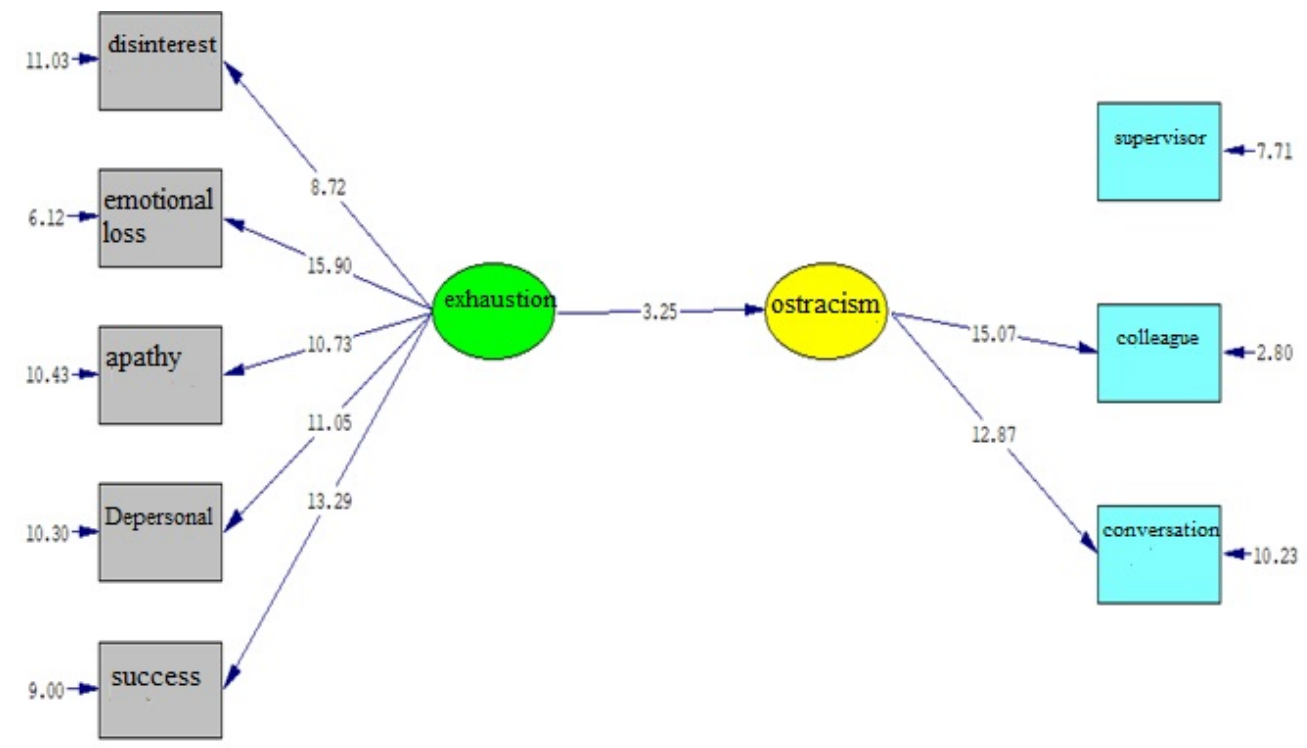

Figure 2. T-coefficient research model about role of emotional exhaustion on workplace ostracism.

success in poor conditions. Sepah Bank's lack of attention to emotional exhaustion and the lack of comprehensive planning in this area seem to have caused this issue. Furthermore, it seems that the existence of social groups among the employees of the bank and the improvement of the bank's environmental conditions have caused some variables, such as the lack of interest in the workplace, to be in a more desirable condition.

On the other hand, it seems that the weakness of the banking system in creating social groups and their high job conflict has caused a static environment in banks. The lack of concentration of bank management in improving the special environment for employees and focusing on the ability of banks to improve the environment related to customers has caused some behavioral and mental variables of bank employees to be unfavorable. Inadequate emotional exhaustion and workplace ostracism can result from inappropriate policies of banks to improve the work environment of employees and their lack of support for social relationships and friendly groups in the banking system.

The results also showed that the supervisor rejection and conversational rejection were in poor conditions and the colleague rejection was in a desirable condition. 
Various studies have addressed this issue and examined the status of organizational rejection. Chung (15) found that organizational rejection is investigated under adverse environmental conditions, which is in line with our results (15). Hsieh and Karatepe found that rejection is due to the employees' lack of attention to the work environment (30).

In the current competitive environment, banks have made customer attraction a priority. This issue has caused attention to the environment of banks with emphasis on customer attraction to become an important and key priority of banks and also not to pay serious attention to employees' job issues. Although every organization, including banks, has always supported its employees, the evidence shows that the organizational system of banks lacks social groups, friendly communications, and a dynamic and attractive environment for employees. This has led to the conditions for the expansion and growth of some undesirable organizational behaviors and attitudes. In other words, rejection is due to the employees' neglect of various aspects of the organization. It seems that the existing problems in the banking system of Iran, including Sepah Bank, have caused difficult conditions for the banking system in Iran. As a result, attention to some organizational issues has not been a key concern of bank managers; and this has resulted in a bad condition regarding ostracism in Sepah Bank.

In interpreting this issue, it should be noted that the existence of appropriate communication among colleagues has led the colleague rejection of Sepah Bank to be in a more favorable condition than other components. In addition, the lack of attention to rejection and lack of comprehensive planning in this area have led to some unfavorable situation of some components of organizational rejection, such as supervisor rejection and conversational rejection. Furthermore, the lack of concern about organizational rejection has led to a lack of attention to the components of rejection in the bank, causing serious problems in this area.

Our results also showed that emotional exhaustion had a significant effect on workplace ostracism of Sepah Bank employees in the Northern provinces of Iran. This has been addressed in various studies. For example, Montazeri (31) found that emotional exhaustion has a significant relationship with some of the occupational problems of individuals, including the proportional to work. Chen et al (32) found after that emotional exhaustion causes organizational problems. Moreover, Welsh et al (33) reported that emotional exhaustion reduces the amount of organizational citizenship behavior. In interpreting this finding, it is important to note that emotional exhaustion always leads to problems in organizations that cause problems in interpersonal and inter-organizational situations. It is natural that problems related to emotional exhaustion interfere with interpersonal and inter- organizational relationships that cause one to move away from their organizational environment. Emotional exhaustion can then lead to workplace ostracism. This issue is due to the problems of emotional exhaustion in relationships of organizations.

Considering this issue, the formation of emotional exhaustion causes disruption in relationships of Sepah Bank, which causes both the individual to move away from the society, as well as the organization to notice the behavioral changes of the individuals. Therefore, emotional exhaustion among the employees of Sepah Bank in the Northern provinces of Iran leads to a significant increase in workplace ostracism among them. In other words, emotional exhaustion had a significant effect on workplace ostracism of employees in our study. It seems that inappropriate job environment of employees causes emotional exhaustion from a mental and behavioral perspective to play a significant role in their work system. In other words, the unfavorable work environment and the lack of proper social relations have led to the conditions for the significant impact of emotional exhaustion in the process of workplace ostracism. In the meantime, the existing banking policies in order to not prioritizing work improvement and not to improve the situation of the work environment have caused the conditions for the emotional exhaustion to have a profound effect on the workplace ostracism of employees. This indicates that the environmental and individual conditions in the banks, especially Sepah Bank in Northern provinces of Iran, are in a situation that has caused the emotional exhaustion to clearly cause the workplace ostracism.

\section{Conclusion}

The results of present study showed that emotional exhaustion, due to its negative functions in the organizational environment, resulted in workplace ostracism in Sepah Bank of Northern provinces of Iran. Thus, increasing emotional exhaustion is expected to increase the rate of workplace ostracism. Therefore, to reduce the workplace ostracism, there is a need to reduce and control the emotional exhaustion. It can also be suggested to improve communication by reducing social ostracism, establishing social groups, and performing recreational activities outside the corporate environment of Sepah Bank.

Conflict of Interests

All authors declare that they have no competing interests.

\section{Ethical Approval}

This research was approved by the Ethics Committee of Islamic Azad University (EC: 981223).

Authors' Contributions

FY and SSh contributed to development of the original idea, study concept and design. FY, SSh, and FA reviewed and edited the 
manuscript. FY and MRM analyzed the data. FY, SSh, and FA wrote the paper. FY, SSh, and MRM participated in acquisition of data. All authors give final approval of the version to be submitted.

Funding/Support

This research did not receive any funding.

Acknowledgments

This article has been taken from the PhD thesis of Firroz Yazarloo (code: 18448216250/738213/97162272948). The authors would like to thank all participants for their sincere collaboration.

\section{References}

1. Mokwa MP. The policy characteristics and organizational dynamics of social marketing. In: Marketing the Public Sector. Routledge: Taylor \& Francis; 2017.

2. Udagedara RS, Allman K. Organizational dynamics and adoption of innovations: a study within the context of software firms in Sri Lanka. J Small Bus Manag. 2019;57(2):450-75. doi: 10.1111/jsbm.12378.

3. Mahfooz Z, Arshad A, Nisar QA, Ikram M, Azeem M. Does workplace incivility \& workplace ostracism influence the employees' turnover intentions? mediating role of burnout and job stress \& moderating role of psychological capital. Int J Acad Res Bus Soc Sci. 2017;7(8):398-413. doi: 10.6007/ IJARBSS/v7-i8/3244.

4. O'reilly JA, Robinson SL. The negative impact of ostracism on thwarted belongingness and workplace contributions. Academy of Management Proceedings. 2009;2009(1):1-7. doi: 10.5465/ambpp.2009.44243707.

5. Eisenberg EM, Goodall HL Jr, Trethewey A. Organizational Communication: Balancing Creativity and Constraint. 6th ed. Bedford/St. Martin's; 2013?

6. Chenji K, Sode R. Workplace ostracism and employee creativity: role of defensive silence and psychological empowerment. Ind Commer Train. 2019;51(6):360-70. doi: 10.1108/ict-05-2019-0049.

7. Bashir F, Nadeem M. The linkage between workplace ostracism and proactive customer service performance in Pakistani banking industry:(a conservation of resource and job embeddedness perspective). American Journal of Management Science and Engineering. 2019 Feb 27. doi: 10.13140/rg.2.2.28937.70244.

8. Hsieh N H. Rawlsian justice and workplace republicanism. Social Theory and Practice. 2005; 31(1): 115-142.

9. Javed S, Shah HS, Bashir T. Workplace Ostracism as a Predictor of Employee Performance and Employee Turnover-Evidence from the Banking Sector. Rome: 42nd International Academic Conference; 2018. doi: 10.20472/iac.2018.042.024.

10. Chung YW, Kim T. Impact of using social network services on workplace ostracism, job satisfaction, and innovative behaviour. Behav Inf Technol. 2017;36(12):1235-43. doi: 10.1080/0144929x.2017.1369568.

11. Coie JD, Terry R, Zakriski A, Lochman J. Early adolescent social influences on delinquent behavior. In: McCord J, ed. Coercion and Punishment in Long-Term Perspectives. Cambridge University Press; 1998. p. 229-44. doi: 10.1017/ cbo9780511527906.014.

12. Gkorezis P, Panagiotou M, Theodorou M. Workplace ostracism and employee silence in nursing: the mediating role of organizational identification. J Adv Nurs. 2016;72(10):23818. doi: 10.1111/jan.12992.

13. Kaya C, Ataman G, Aydin B.Y. Workplace ostracism and work engagement: the moderating role of neuroticism. International Journal of Business and Management. 2017;5(2):17-28. doi: 10.20472/bm.2017.5.2.002.

14. Ferris DL, Brown DJ, Berry JW, Lian H. The development and validation of the Workplace Ostracism Scale. J Appl Psychol. 2008;93(6):1348-66. doi: 10.1037/a0012743.

15. Chung YW. Workplace ostracism and workplace behaviors: a moderated mediation model of perceived stress and psychological empowerment. Anxiety Stress Coping. 2018;31(3):304-17. doi: 10.1080/10615806.2018.1424835.

16. Lee RT, Ashforth BE. A meta-analytic examination of the correlates of the three dimensions of job burnout. J Appl Psychol. 1996;81(2):123-33. doi: 10.1037/00219010.81.2.123.

17. Maslach C, Leiter MP, Fink G. Stress: Concepts, Cognition, Emotion, and Behavior. Handbook in Stress Series, Volume 1. Academic Press; 2016.

18. Tourigny L, Baba VV, Han J, Wang X. Emotional exhaustion and job performance: the mediating role of organizational commitment. The International Journal of Human Resource Management. 2013;24(3):514-32. doi: 10.1080/09585192.2012.694109.

19. Swider BW, Zimmerman RD. Born to burnout: a metaanalytic path model of personality, job burnout, and work outcomes. J Vocat Behav. 2010;76(3):487-506. doi: 10.1016/j. jvb.2010.01.003.

20. Cropanzano R, Rupp DE, Byrne ZS. The relationship of emotional exhaustion to work attitudes, job performance, and organizational citizenship behaviors. J Appl Psychol. 2003;88(1):160-9. doi: 10.1037/0021-9010.88.1.160.

21. Halbesleben JRB, Buckley MR. Burnout in organizational life. J Manage. 2004;30(6):859-79. doi: 10.1016/j.jm.2004.06.004.

22. Maslach C, Jackson SE, Leiter MP, Schaufeli WB, Schwab RL. Maslach Burnout Inventory. Palo Alto, CA: Consulting Psychologists Press; 1986.

23. Abubakar AM, Yazdian TF, Behravesh E. A riposte to ostracism and tolerance to workplace incivility: a generational perspective. Pers Rev. 2018;47(2):441-57. doi: 10.1108/pr-072016-0153.

24. Kwan HK, Zhang X, Liu J, Lee C. Workplace ostracism and employee creativity: an integrative approach incorporating pragmatic and engagement roles. J Appl Psychol. 2018;103(12):1358-66. doi: 10.1037/apl0000320.

25. Mohammadbeigi A, Mohammadsalehi N, Aligol M. Validity and reliability of the instruments and types of measurments in health applied researches. J Rafsanjan Univ Med Sci. 2015;13(12):1153-70. [Persian].

26. Heydari M. Handbook of Measuring Validity and Reliability in Cultural and Social Research. Publications University of Mashhad; 2009.

27. Hassanzadeh Rangi N, Allahyari T, Khosravi Y, Zaeri F, Saremi M. Development of an Occupational Cognitive Failure Questionnaire (OCFQ): evaluation validity and reliability. Iran Occup Health. 2012;9(1):29-40. [Persian].

28. Amiri $M$, Asadi MR, Raghab F. investigating the job burnout among bank employees and improvement strategies. Bus Manage. 2011;3(7):37-92. [Persian].

29. Thompson MJ, Carlson DS, Kacmar KM, Vogel RM. The cost of being ignored: emotional exhaustion in the work and family domains. J Appl Psychol. 2020;105(2):186-195. doi: 10.1037/ apl0000433.

30. Hsieh H, Karatepe OM. Outcomes of workplace ostracism among restaurant employees. Tour Manag Perspect. 
2019;30:129-37. doi: 10.1016/j.tmp.2019.02.015.

31. Montazeri N. The Impact of Emotional Exhaustion and JobProportion on Individual's Organizational Deviant Behavior [dissertation]. Tehran: Allameh Tabataba'i University; 2016. [Persian].

32. Chen $\mathrm{KY}$, Chang $\mathrm{CW}$, Wang $\mathrm{CH}$. Frontline employees' passion and emotional exhaustion: the mediating role of emotional labor strategies. Int J Hosp Manag. 2019;76:163-72. doi: 10.1016/j.ijhm.2018.05.006.

33. Welsh DT, Baer MD, Sessions H. Hot pursuit: the affective consequences of organization-set versus self-set goals for emotional exhaustion and citizenship behavior. J Appl Psychol. 2020;105(2):166-85. doi: 10.1037/apl0000429. 